\title{
Effectiveness of supplementary blended flour based on chickpea and cereals for the treatment of infants with moderate acute malnutrition in Iran: A randomized clinical trial
}

\author{
Roghayeh Javan ${ }^{1,2}$, Akram Kooshki $^{3}$, Monavvar Afzalaghaee ${ }^{4}$, Mitra Aldaghi $^{5}$, Mahdi Yousefi ${ }^{6}$
}

${ }^{1}$ MD-PhD of Persian Medicine, Assistant Professor, Traditional and Complementary Medicine Research Center, Sabzevar University of Medical Sciences, Sabzevar, Iran

${ }^{2}$ Student Research Committee, Department of Persian Medicine, Faculty of Persian and Complementary Medicine, Mashhad University of Medical Sciences, Mashhad, Iran

${ }^{3} \mathrm{Ph} . \mathrm{D}$. of Nutrition, Associate Professor, Department of Nutrition \& Biochemistry, Faculty Member of Medicine School, Sabzevar University of Medical Sciences, Sabzevar, Iran

${ }^{4}$ MD, Social Medicine Specialist, Assistant Professor, School of Health, Management and Social Determinants of Health Research Center, Mashhad University of Medical Sciences, Mashhad, Iran

${ }^{5}$ MD, Pediatrics Gastroenterologist, Assistant Professor, Department of Pediatrics, Sabzevar University of Medical Sciences, Sabzevar, Iran

${ }^{6}$ MD-PhD of Persian Medicine, Assistant Professor, Department of Persian Medicine, Faculty of Persian and Complementary Medicine, Mashhad University of Medical Sciences, Mashhad, Iran

\section{Type of article: Original}

\begin{abstract}
Background: Despite the decreasing rate of under nutrition children in recent years overall, the negative affect in growth and development make it as a main concern in the world. Applying an available and appropriate supplementary food is a major approach in treating children with Moderate Acute Malnutrition (MAM).

Objective: To compare the effectiveness of a new supplementary blended flour (containing chickpea, rice, wheat and barley, named Shadameen) in combination with multivitamin/mineral supplement and nutritional counseling versus multivitamin/mineral supplement and nutritional counseling alone, in the treatment of children with MAM.

Methods: This randomized controlled trial study was conducted at Heshmatiyeh Hospital in Sabzevar city in Iran, from January 2016 to December 2016. Seventy infants, aged 9 to 24 months with MAM who were referred from urban health centers to the hospital clinic were included. They were randomly assigned to receive, for about 3 months, either multivitamin / mineral supplement and nutritional counseling alone or in combination with an extra supplementary blended food. We analyzed weight, length, weight for length $Z$ score (WLZ), weight for age $\mathrm{Z}$ score (WAZ) and length for weight $\mathrm{Z}$ score (LAZ), along with recovery rate and adverse events among the two groups. The data were analyzed using SPSS version 16 . We used statistics, Chi-square, independent $t$-test, and Fisher's exact test for the analyses of primary and secondary outcomes.

Results: The food supplementation infant's mean weight and WLZ and WAZ were greater compared with the other group $(0.81 \pm 0.29 \mathrm{gr}$ and $0.55 \pm 0.33 \mathrm{gr}, \mathrm{p}=0.002),(0.36 \pm 0.36$ and $0.02 \pm 0.52, \mathrm{p}=0.003),(0.40 \pm 0.33$ and $0.09 \pm 0.37, \mathrm{p}=0.001)$. The recovery rate in the food supplemented group was significantly higher than the other group $(68.4 \%, 31.6 \%, \mathrm{p}=0.001)$. No adverse reactions were observed. There were no significant differences in LAZ at the end of the study between the two groups $(\mathrm{p}=0.53)$.

Conclusion: This study showed that Shadameen in combination with multivitamin/mineral and counselling therapy can be more effective in decreasing the wasting rate of children with MAM than vitamin/mineral and
\end{abstract}

\section{Corresponding author:}

Assistant Professor Dr. Mahdi Yousefi, Department of Persian Medicine, Faculty of Persian and Complementary Medicine, Mashhad University of Medical Sciences, Mashhad, Iran.

Tel: +98.5138829279, Fax:+98.5138535980, Email: YousefiM@mums.ac.ir

Received: May 19, 2017, Accepted: June 24, 2017, Published: December 2017

iThenticate screening: June 11, 2017, English editing: November 12, 2017, Quality control: December 14, 2017

This article has been reviewed / commented by four experts

(C) 2017 The Authors. This is an open access article under the terms of the Creative Commons Attribution-NonCommercialNoDerivs License, which permits use and distribution in any medium, provided the original work is properly cited, the use is non-commercial and no modifications or adaptations are made. 
counseling therapy alone.

Trial registration: The trial was registered at the Iranian Registry of Clinical Trials (http://www.irct.ir) with the Irct ID: IRCT2015040921670N1.

Funding: This study was financially supported by the vice chancellor for research office, Mashhad University of Medical Sciences.

Keywords: Malnutrition, Children, Supplementary food, Chickpea, Cereals

\section{Introduction}

Pediatric malnutrition (undernutrition), described as a state of imbalance between nutrient requirements and intake, leads to deficits of protein, energy or micronutrients, affecting growth and development negatively (1). Malnutrition is considered as one of the leading causes of morbidity and mortality in children under the age of five in developing countries (2). According to a World Health Organization estimation in 2014, globally, 50 million children under five years of age were wasted and the wasting rate was 7.5 percent $(3,4)$. Statistics from Iran, in 2007, reported 5.9\% moderate and $1.6 \%$ severe wasting, $12.7 \%$ moderate and 3.9\% severe stunting prevalence in under 6 -year old children in South Khorasan (5). Undernutrition refers to acute malnutrition (wasting), chronic malnutrition (Stunting), kwashiorkor, marasmus, marasmic kwashiorkor and micronutrient deficiencies. Anthropometric variables are used for definition of malnutrition (6). Malnutrition can be classified as moderate or severe in children under five years of age. Moderate malnutrition or moderate acute malnutrition (MAM) is defined as a weight for height or length Z score (WHZ, WLZ) between -2 and -3 . Severe malnutrition or severe acute malnutrition (SAM) is defined as a WHZ of below -3 or a mid-upper arm circumference (MUAC) of less than $115 \mathrm{~mm}$, or the presence of bilateral edema $(6,7)$. Inadequate food intake, which is one of the immediate causes of malnutrition, could be reversed by food interventions. These interventions include two broad approaches. In the first approach, nutritional counseling is given to families when they have access to all foods needed for feeding their children. Using special recipes made with locally available ingredients and home processing of foods, such as soaking, germination, malting, and fermentation, increase the nutritional content of family food. The other approach (externally supplementary feeding programs) are practicable where food availability is inadequate (8). A review of implemented programs by a number of agencies or local governments has showed that, for the treatment of MAM, generally, there is a greater emphasis on providing food supplements than giving nutritional counseling to improve locally available family foods $(8,9)$. Two main categories of externally provided food supplements include lipid-based nutrient supplements (LNS), which are as ready-to-use therapeutic food (RUTF) with a high lipid content, and blended food supplements which are mixtures of different food ingredients such as corn, soya, oils, sugar, legumes or others (8). Many studies were conducted to evaluate different ingredients' effectiveness on malnutrition treatment (10-14). Multivitamins/minerals and counseling therapy are generally applied for malnutrition treatment in children in Iran. Although many nutritional interventions were conducted on childhood malnutrition (15), till now, there has been no study on a supplementary food with locally available nutritional ingredients for malnutrition treatment in Iran. A blended food formulated with a mixture of chickpea, barley, wheat, rice and sugar has been introduced in Traditional Persian Medicine to treat wasting. In the present randomized controlled trial, we compared the effects of blended food supplement (named as Shadameen) on treatment of MAM. The results of this study could help us to access a native food supplement for decreasing wasting rate.

\section{Material and Methods}

\subsection{Study design}

This study was a randomized, investigator- blinded (single blind), controlled clinical trial that that assessed the treatment of MAM in two parallel groups of children for a period of 84 days. The study was conducted from January 2016 to December 2016.

\subsection{Participants}

The research children population was selected from urban areas of Sabzevar, Iran. Sabzevar is a city in the north east of Iran with a population of over 364,553. Children are routinely brought to health centers by mothers for evaluating their growth charts based on a planned schedule with the health ministry of Iran. Children aged 9 to 24 months were screened and assessed primarily by health workers, for having criteria of MAM (-2> WLZ $\geq-3)$ according to Iran pediatrics standard growth charts in 17 main urban health centers. These health centers are located in different areas of the city and cover the city's total population through their health services. Children who had suspicion of MAM were referred by health workers to the pediatric clinic of Heshmatiyeh Hospital in Sabzevar city for evaluation of any diseases by a physician. Heshmatiyeh is a specialty and general university hospital. This hospital is the referral center of the eastern area of Khorasan Razavi province, and has a specialized pediatrics ward and clinic. 


\subsection{Selection criteria}

The inclusion criteria for participation in this study were: 1) age between 9 to 24 months, 2) confirmed satisfaction of parents with participating in the study, and 3) presence of criteria of MAM $(-2>$ WLZ $\geq-3)$. The exclusion criteria were any acute or chronic illness, food allergy, congenital abnormality or severe malnutrition [weight-forlength Z-scores (WLZ) or length- for- age Z-score LAZ $\leq-3$ ] in children.

\subsection{Sampling}

\subsubsection{Sample size}

The planned sample size for the study was 30 infants per group calculated from the expected difference in the primary outcome, i.e. weight gain, among those provided Shadameen or those not provided it. This sample size would be sufficient to detect at least $300 \mathrm{mg}$ mean difference in weight gain (expected according to the previous studies) between the two groups, at a significance level of 0.05 with $80 \%$ power with an expected SD of $200 \mathrm{mg}$. Given the assumption of dropouts during the study time, this sample size was added by up to $15 \%$, so finally, 35 children were considered for each group.

\subsubsection{Sampling method}

After primary physical examination of children who were referred to the hospital clinic by the physician, initial laboratory tests were requested to rule out any underlying disease. A trained investigator who was blinded to the child's specified group, assessed anthropometric indicators, using standard methods: weight was measured with a Seca 334 digital scale to the nearest $5 \mathrm{~g}$, length was measured in triplicate to the nearest $0.1 \mathrm{~cm}$ with a measuring rod with Seca baby scales in lying position. Only children with no acute or chronic illness, food allergy, congenital abnormality or severe malnutrition [weight-for-length Z-scores (WLZ) or length-for-age Z score (LAZ) $\leq-3$ ] were included. The mothers of children who met enrollment criteria gave verbal and written consent before randomization.

\subsection{Blinding and allocation}

Children were randomly allocated into two different groups. The intervention group received a blended supplementary food in addition to multivitamins/mineral supplement and nutritional counselling therapy (group 1 or Shadameen), while the other group (group 2) received only multivitamins/mineral supplement and nutritional counseling therapy. The investigator who performed the clinical assessments was blinded to the child's specified group. The children and mothers could not be blinded because one group did not offer supplementary foods.

\subsection{Data collection}

On enrollment, an interview was conducted on each child's demographic characteristics, appetite and the 24-hour diet recall with mothers. Nutrition counseling was also provided to all mothers in a session at the beginning of the study. Ferrous sulfate drop and Zincovit B syrup were distributed in amounts sufficient for 2 weeks during intervention period. The blended food supplement which was prepared in packages of 1000 grams was given to the mothers with a recipe once every two weeks. This food must be served with milk as a porridge. Children returned every 2 weeks for follow-up for up to 6 visits, at each time, anthropometric measurements were repeated, adverse event reports were taken and additional supplementary food and Ferrous sulfate and Zincovit B were distributed for the next two weeks.

\subsection{Interventions}

The blended supplementary food was contained chickpea, barley, wheat, rice and sugar in equal proportion, so 200 $\mathrm{mg}$ of each gradient was needed for providing $1000 \mathrm{mg}$ of the blended food. The powder form food supplement was prepared in packages of 1000 grams, given to the mothers with a recipe once every two weeks. Mothers were requested to serve 70 grams of this food supplement twice a day, as a gruel prepared with milk and cooked the mixture for at least $10 \mathrm{~min}$, to be consumed in addition to the usual home diet. Ferrous sulfate drop (Amin Esfahan, Iran) prescribed as 15 drops per day $(0.6 \mathrm{ml})$ and Zincovit B (Alborz Darou, Iran) syrup prescribed as $5 \mathrm{ml}$ per day. Each 15 drops has $15 \mathrm{mg}$ Iron and each $5 \mathrm{ml}$ of Zincovit B contains 5mg Zinc, 5mg Vitamin B1, 1.8mg Vitamin B2, $1.6 \mathrm{mg}$ Vitamin B6, and $16 \mathrm{mg}$ Nicotinamide. The micronutrient and protein content of the Shadameen is shown in Table 1. Children returned every 2 weeks for follow-up for up to 6 visits, at each time, anthropometric measurements were repeated, adverse event reports were taken and additional supplementary food and Ferrous sulfate and Zincovit B were distributed for the next two weeks. We gave the parents a daily usage report form of Shadameen and requested them to bring it to every follow-up visit. 
Table 1. Nutrients provided in $70 \mathrm{~g}$ Shadameen for children, in comparison to World Health Organization/Food and Agriculture Organization (WHO/FAO) Recommended Nutrient Intakes (RNI)(16)

\begin{tabular}{|l|l|l|l|l|}
\hline Nutrient & \multirow{2}{*}{ Unit } & \multirow{2}{*}{ Shadameen } & WHO/ FAO RNI \\
\cline { 4 - 6 } & & & $7-12$ month & $12-36$ months $^{\prime}$ \\
\hline Dry mass of supplementary food & gr & 67.69 & & \\
\hline Moisture & gr & 2.3 & - & - \\
\hline Energy & kcal & 272.63 & - & - \\
\hline Protein & gr & 9.73 & 10.5 & 11.9 \\
\hline Fat & gr & 1.75 & $35 \%$ energy $^{1}$ & $25-35 \%$ energy $^{1}$ \\
\hline Carbohydrate & gr & 8.05 & - & - \\
\hline Dietary fiber & gr & 0.93 & - & - \\
\hline Vitamin A & $\mathrm{mg}$ & 0.148 & 400 & 400 \\
\hline Vitamin B1 & $\mathrm{mg}$ & 1.54 & 0.3 & 0.5 \\
\hline Vitamin B2 & $\mathrm{mg}$ & 0.14 & 0.4 & 0.5 \\
\hline Vitamin B3 & $\mathrm{mg}$ & 0 & 4 & 6 \\
\hline Vitamin B6 & $\mathrm{mg}$ & 4.2 & 0.3 & 0.5 \\
\hline Vitamin B12 & $\mathrm{mg}$ & 0 & 0.7 & 0.9 \\
\hline Vitamin C & $\mathrm{mg}$ & 27.16 & 30 & 30 \\
\hline Vitamin D & $\mathrm{mg}$ & 0.282 & 5 & 5 \\
\hline Vitamin E & $\mathrm{mg}$ & 0.009 & 2.7 & 5 \\
\hline Calcium & $\mathrm{mg}$ & 39.48 & 400 & 500 \\
\hline Iodine & $\mathrm{mg}$ & 0 & 90 & 90 \\
\hline Iron & $\mathrm{mg}$ & 3.5 & $18.6^{2}$ & $11.6^{2}$ \\
\hline Magnesium & $\mathrm{mg}$ & 45.08 & 54 & 60 \\
\hline Phosphorus & $\mathrm{mg}$ & 147.35 & - & - \\
\hline Potassium & $\mathrm{mg}$ & 119.63 & - & $3510^{3}$ \\
\hline Selenium & $\mu \mathrm{g}$ & 0.0004 & 10 & 17 \\
\hline Zinc & $\mathrm{mg}$ & 3.36 & $8.44^{4}$ & $8.34^{4}$ \\
\hline
\end{tabular}

${ }^{1}$ Gradual reduction from $40-60 \% \mathrm{E}$ in o-6 months , depending on physical activity, to $35 \% \mathrm{E}$ in $6-24 \mathrm{~m} 0$ nths and $25-35 \% \mathrm{E}$ in 2-18 years (17); ${ }^{2} \mathrm{RNI}$ for an assumed bioavailability of $5 \%$; ${ }^{3}$ Recomended for children more than 2 years of age (18); ${ }^{4} \mathrm{RNI}$ for low bioavailability

\subsection{Outcome}

Primary outcomes included rates of gain in weight, length and Z-score weight-for-length changes. Secondary outcomes were recovery proportion and adverse events.

\subsection{Data analysis:}

Anthropometric indexes were based on the WHO's 2006 Child Growth Standards (19), calculated by using Anthro v 3.2.2 (WHO) (21). Data were analyzed with SPSS software version 16.0 (SPSS, Inc., Chicago, IL, USA). We used per protocol method for analyzing data. A comprehensive analysis of potential confounders at baseline was performed to assess the extent, if any, of baseline treatment group imbalances for sex and family income, breastfeeding, weight-for-Length Z score (WLZ), maternal education, parity, and site. Normality was tested with the Kolmogorov-Smirnov test. In cases of normality, independent-samples t-test was used, while without normality, Mann-Whitney test was used. Pearson Chi-square test was used to analyze nominal variables. When more than $20 \%$ of the table's expected frequency were below 5, comparison between groups were made, using Fisher's exact test for nominal variables. P-values $<0.05$ were considered to be statistically significant.

\subsection{Research ethics}

The proposal for this thesis research was approved by the Ethics Committee of Mashhad University of Medical Sciences. The Ethics Committee approved the study with the number IR.MUMS.REC.1394.528 on October 7, 2015, the enrollment of patients began on January 25, 2015, and the study continued until December 30, 2016. This study was registered in the Iranian Registry of Clinical Trials (irct.ir) with the ID: IRCT2015112125168N1 in January 22, 2016. The participant parents were informed about the aim and object of the study, oral and written informed consent in native language (Persian) was obtained from all parents prior to the study. We were also committed to allow all of the participants to leave the study anytime they wanted. 


\section{Results}

A total of 142 children who were suspicious to MAM were referred to the hospital clinic by health workers, and 70 of them were eligible for recruitment. The final number of participants was 35 in each group of the study; 33 $(94.2 \%)$ and $31(88.5 \%)$ completed the study for the Shadameen (group 1) and control (group 2), respectively (Figure 1). The main reasons for dropout were unwillingness of mothers and withdrawing from the study because of lack of time to bring the infant to the clinic. There were no differences among the 2 groups at baseline for age, sex, anthropometry, appetite, education and employment of parents, family income or number of children in the family (Table 2).

\section{Enrollment}

Children suspicious to moderate acute malnutrition assessed for eligibility $(n=142)$

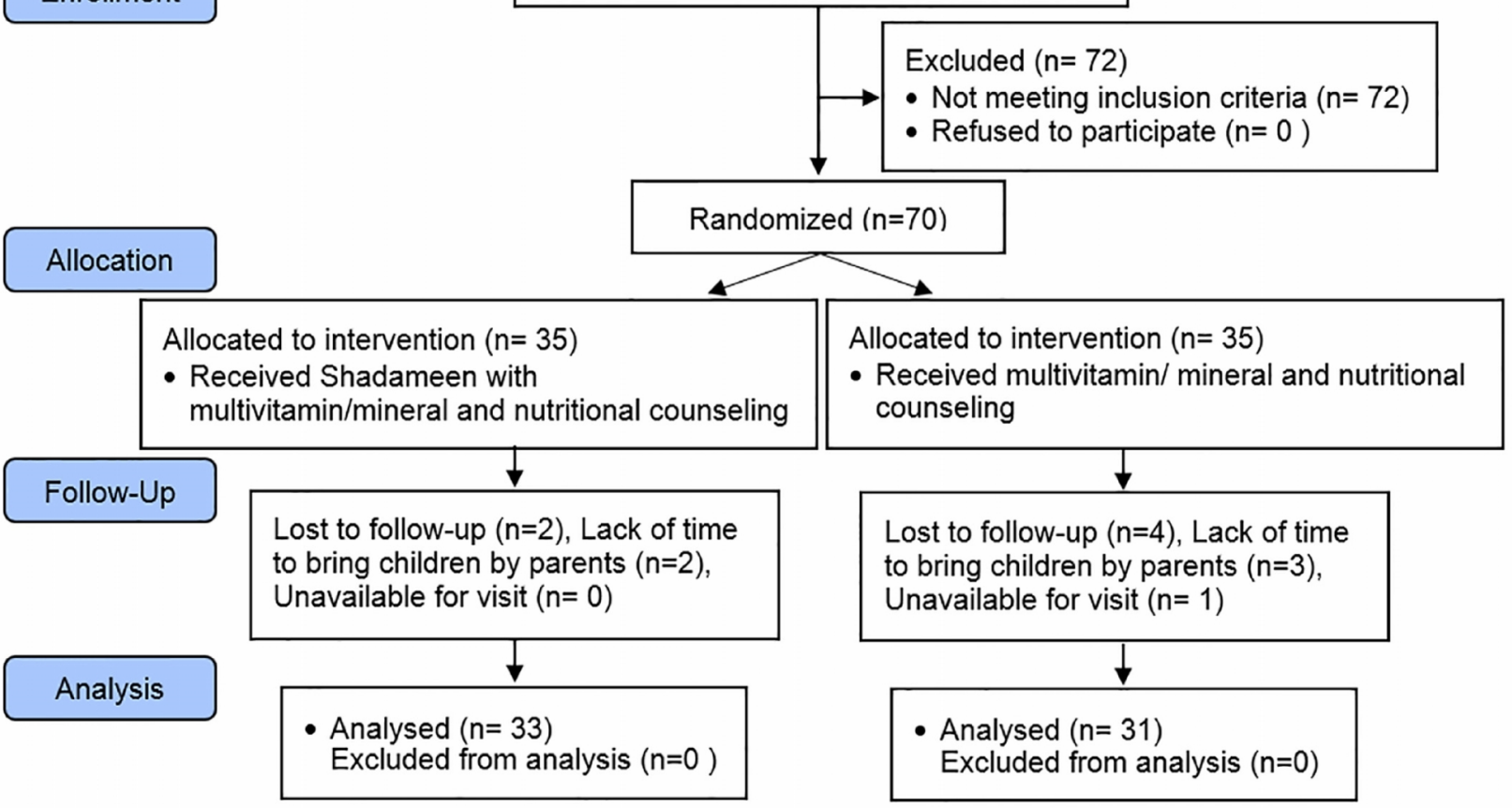

Figure 1. CONSORT flowchart of participants.

Table 2. Characteristics of infants in baseline

\begin{tabular}{|l|l|l|l|}
\hline Variable & Groups & \multicolumn{2}{|l|}{} \\
\cline { 2 - 4 } & $\begin{array}{l}\text { Group 1 (vitamin \& } \\
\text { mineral+ counselling) }\end{array}$ & $\begin{array}{l}\text { Group 2 (Shadameen }+ \\
\text { vitamin\& mineral) }\end{array}$ & p-value \\
\hline Maternal education level [n ( \%) low literacy] & $10(28.5)$ & $14(40)$ & 0.53 \\
\hline Mather employed [n (\%)] & $3(8.5)$ & $0(0.0)$ & 0.24 \\
\hline Father employed [n (\%)] & $29(82.8)$ & $32(91.4)$ & 0.46 \\
\hline Family income (10000 Rials) & $935 \pm 55$ & $922 \pm 43$ & 0.94 \\
\hline No. of children & $1.64 \pm 0.69$ & $1.71 \pm 0.71$ & $0.64^{\mathrm{a}}$ \\
\hline Eating mothers milk Up to now [n (\%)] & $31(88.5)$ & $28(80)$ & 0.51 \\
\hline Appetite [n (\%) low appetite] & $29(82.8)$ & $31(88.5)$ & 0.71 \\
\hline Infants sex [n (\%) female] & $23(65.7)$ & $20(57.1)$ & 0.46 \\
\hline Infants age (mean) & $13.40 \pm 3.34$ & $12.80 \pm 3.38$ & $0.54^{\mathrm{a}}$ \\
\hline Infants weigh at the beginning of study & $7.20 \pm 0.62$ & $7.05 \pm 0.64$ & 0.31 \\
\hline Infants length at the beginning of study & $71.83 \pm 3.57$ & $70.92 \pm 3.32$ & 0.27 \\
\hline Infants WLZ score at the beginning of Study & $-2.10 \pm 0.077$ & $-2.12 \pm 0.13$ & $0.26^{\mathrm{a}}$ \\
\hline Infants WAZ score at the beginning of study & $-2.43 \pm 0.27$ & $-2.5 \pm 0.26$ & 0.24 \\
\hline Infants LAZ score at the beginning of study & $-1.78 \pm 0.49$ & $-1.86 \pm 0.43$ & 0.46 \\
\hline
\end{tabular}

${ }^{\mathrm{a} U}$ mann-whitney test 
No adverse reactions were observed. At the end of the 84 days intervention period, the Shadameen group showed a superior rate of weight gain, WLZ and WAZ increase in comparison with the other group (Table 3). The mean weight, WLZ and WAZ increments between baseline and end of intervention were significantly greater in the Shadameen group $(0.81 \pm 0.29$ gr $)(\mathrm{p}=0.002),(0.36 \pm 0.36) \quad(\mathrm{p}=0.003),(0.40 \pm 0.33) \quad(\mathrm{p}=0.001)$ compared with $0.55 \pm 0.33 \mathrm{gr}, 0.02 \pm 0.52$ and $0.09 \pm 0.37$ in group 2. Although the mean length and LAZ increments between baseline and end of intervention was greater in the Shadameen group $(3.36 \pm 1.04 \mathrm{~cm})(0.17 \pm 0.390)$ in comparison to group 2, this rate did not differ significantly $(3.10 \pm 1.02 \mathrm{~cm})(\mathrm{p}=0.31),(0.10 \pm 0.39)(\mathrm{p}=0.53)$. The recovery rate was considered as number of children who had WLZ greater than -2 at the end of intervention period. The proportion of children who recovered was significantly higher in the Shadameen group [26 n (68.4\%)] compared with [12 $\mathrm{n}$ $(31.6 \%)]$ the other group $(\mathrm{p}=0.001)$.

Table 3. Differences in anthropometric indices from baseline to end

\begin{tabular}{|l|l|l|l|}
\hline Variable & Groups & p-value \\
\cline { 2 - 4 } & $\begin{array}{l}\text { Group 1 (vitamin } \\
\text { \& mineral) }\end{array}$ & $\begin{array}{l}\text { Group 2 (Shadameen }+ \\
\text { vitamin\& mineral) }\end{array}$ & \\
\hline Mean weight increments (gr) & $0.55 \pm 0.33$ & $0.81 \pm 0.29$ & $0.002^{*}$ \\
\hline Mean length increments (cm) & $3.10 \pm 1.02$ & $3.36 \pm 1.04$ & 0.31 \\
\hline Mean Z score weight for height increments & $0.02 \pm 0.52$ & $0.36 \pm 0.36$ & $0.003^{*}$ \\
\hline Mean Z score weight for age increments & $0.09 \pm 0.37$ & $0.40 \pm 0.33$ & $0.001^{*}$ \\
\hline Mean Z score length for age increments & $0.10 \pm 0.39$ & $0.17 \pm 0.39$ & 0.53 \\
\hline Recovery [n (\%)] ( Z score weight for Height> -2 & $12(31.6)$ & $26(68.4)$ & $0.001^{*}$ \\
\hline
\end{tabular}

\section{Discussion}

The result of this study showed that given blended supplementary food in addition to vitamin-mineral therapy and nutritional counseling is more effective in treating moderate wasting than vitamin-mineral therapy and nutritional counseling alone. Legumes and cereal mixtures are recommended for supplementary feeding of malnourished children (22). Chickpea has a high nutrient composition with a good source of high quality protein similar to that of soya. It is a good source of carbohydrates, minerals (calcium, phosphorous, magnesium, potassium and iron), vitamins (thiamine and niacin) and a low amount of lipids which are rich in nutritionally important unsaturated fatty acids such as linoleic and oleic acid (23-25). Many studies have been carried out to examine effectiveness of supplementary blended food with different ingredients such as corn/soya, rice/soya, for treatment of MAM $(26,27)$. Most of them compared RUTF with supplementary blended foods (11). Recovery rate in Shadameen (68.4\%) is almost same as some other similar studies. Nackers et al. examined the effects of two food supplements on weight gain and recovery of 451 children with MAM in Niger. One group of children received conventional CSB (corn/ soy-blend), and the other group received RUTF (Plumpy'nut; Nutriset). Children who received CSB (corn/ soyblend) had a recovery rate of $64.4 \%$ compared with $79.1 \%$ in RUSF ( $<<0.001)$ (28). Although weight, WAZ and WLZ changes were significant in our study, Shadameen did not significantly change length increment. Many studies have shown significant differences in linear growth by intervention with more than 6 months duration $(29,30)$. Dietary quality can modify the relationship between food quantity and linear growth (31), thus type of the supplementary food ingredients may have a role in linear growth. Despite the little amount of fat in Shadameen, this supplement is rich in protein and vitamin B1, B2, B6, Magnesium, Phosphorus and partly in zinc. Investigation of potential use of chickpeas in infant follow-on formula, found that the protein content was high and that they meet the amino acid requirements of the WHO/FAO protein reference for children at 0-24 month's (32). Protein and zinc have a strong effect on linear growth. Assuming that our supplementary food is rich in protein, these findings emphasize the likely multifactorial basis of stunting in young children. The duration of intervention in our study was only 84 days. More long-term intervention may be needed to influence length increment positively. As with our results, studies with the same intervention duration (3 months), showed no significant differences in LAZ (33). Unlike most previous studies conducted with other supplementary foods, our blended food was not fortified, so it could be deduced that differences between the two groups, may be the real effect of this blended supplementary food. Most interventions in MAM treatment were done in rural areas in which food is insecure $(27,33,34)$. Our study was carried out in urban areas so the differences between food security may affect the results. Zinc and multivitamin supplementation did not reduce the rate of wasting, stunting and underweight in Tanzanian children aged 6-84 (35). Adding zinc to a Lipid-Based Nutrient Supplements did not change its effect on stunting or wasting (36). A systematic review on educational interventions about child feeding showed a modest effect on weight and linear growth (31). We found a small increase in WAZ and WHZ in group 2. As a limitation, we did not have a non- 
intervention group, so the exact efficacy of intervention in group 2 was not clear. Inability to measure the exact dietary intake and supplementary food consumption at home was another limitation in this study. Usage of Shadameen may not perform on the basis of a given recipe, and there is also the probability of share food. A home visit by health care workers might improve intake of food and rate of weight gain. No evidence of allergy was found in this study.

\section{Conclusions}

This study showed that Shadameen in combination with vitamin-mineral and counselling therapy, can be more effective in decreasing the rate of wasting in children with MAM than vitamin-mineral and counselling therapy alone. Since ingredients of this food supplement are cheap and easily available, its use in the treatment of child malnutrition can be very remedial. Future studies with large sample size and long term intervention are needed.

\section{Acknowledgments:}

This study is a part of the Ph.D. dissertation and is supported and funded by the vice chancellor for research office, Mashhad University of Medical Sciences. The authors appreciate all the staff members, nurses who worked in the pediatric clinic of Heshmatiyeh hospital and the vice chancellor for research of Sabzevar University of Medical Science who helped us do this project. We sincerely appreciate the support of the participating children and their parents.

\section{Trial Registration:}

The trial was registered at the Iranian Registry of Clinical Trial (http://www.irct.ir) with the Irct ID: IRCT2015112125168N1 in January 22, 2016.

Funding: This study was financially supported by the vice chancellor for research office, Mashhad University of Medical Sciences.

\section{Conflict of Interest:}

There is no conflict of interest to be declared.

\section{Authors' contributions:}

All authors contributed to this project and article equally. All authors read and approved the final manuscript.

\section{References:}

1) Mehta NM, Corkins MR, Lyman B, Malone A, Goday PS, Carney L, et al. Defining pediatric malnutrition: a paradigm shift toward etiology-related definitions. Journal of J Parenter Enteral Nutr. 2013; 37(4): 46081. doi: 10.1177/0148607113479972. PMID: 23528324.

2) Amsalu S, Tigabu Z. Risk factors for severe acute malnutrition in children under the age of five: A casecontrol study. Ethiop j health dev. 2016; 22(1). doi: 10.4314/ejhd.v22i1.10058.

3) UNICEF-WHO-The World Bank Group. Joint Child Malnutrition Estimates. In United Nations Children's Fund. New York, Geneva, Washington DC: UNICEF, WHO, The World Bank; 2015.

4) Hoseini BL, Emami Moghadam Z, Saeidi M, Rezaei Askarieh M, Khademi G. Child malnutrition at different world regions in 1990-2013. Int J Pediatr. 2015; 3(5.1): 921-32. doi: 10.22038/ijp.2015.4748.

5) Sharifzadeh G, Mehrjoofard H, Raghebi S. Prevalence of malnutrition in under 6-year olds in South Khorasan, Iran. Iran J Pediatr. 2010; 20(4): 435-41. PMID: 23056743, PMCID: PMC3446098.

6) Schoonees A, Lombard M, Musekiwa A, Nel E, Volmink J. Ready - to - use therapeutic food for home based treatment of severe acute malnutrition in children from six months to five years of age. The Cochrane Library. 2013. doi: 10.1002/14651858.CD009584.pub2.

7) Lenters L, Wazny K, Bhutta ZA. Management of Severe and Moderate Acute Malnutrition in Children. Reproductive, Maternal, Newborn, and Child Health. 2016: 205. PMID: 27227221

8) Lazzerini M, Rubert L, Ronfani L, Pani P, Montico M. Specially formulated foods for treating children with acute moderate malnutrition in low- and middle-income countries. (Protocol) Cochrane Database of Systematic Reviews 2012, Issue 1. Art. No.: CD009584. DOI: 10.1002/14651858.CD009584.

9) Ashworth A, Ferguson E. Dietary counseling in the management of moderate malnourishment in children. Food Nutr Bull. 2009; 30(3_supp13): S405-33. doi: 10.1177/15648265090303S304. PMID: 19998865. 
10) Lazzerini M, Rubert L, Pani P. Specially formulated foods for treating children with moderate acute malnutrition in low- and middle-income countries. (Review) Cochrane Database of Systematic Reviews 2013, Issue 6. Art. No.: CD009584. DOI: 10.1002/14651858

11) Karakochuk C, van den Briel T, Stephens D, Zlotkin S. Treatment of moderate acute malnutrition with ready-to-use supplementary food results in higher overall recovery rates compared with a corn-soya blend in children in southern Ethiopia: an operations research trial. The Am J Clin Nutr. 2012; 96(4): 911-6. doi: 10.3945/ajen.111.029744. PMID: 22952175.

12) Ahmed T, Choudhury N, Hossain MI, Tangsuphoom N, Islam MM, de Pee S, et al. Development and acceptability testing of ready-to-use supplementary food made from locally available food ingredients in Bangladesh. BMC pediatr. 2014; 14(1): 164. doi: 10.1186/1471-2431-14-164. PMID: 24972632.

13) LaGrone LN, Trehan I, Meuli GJ, Wang RJ, Thakwalakwa C, Maleta K, et al. A novel fortified blended flour, corn-soy blend "plus-plus," is not inferior to lipid-based ready-to-use supplementary foods for the treatment of moderate acute malnutrition in Malawian children. Am J Clin Nutr. 2012; 95(1): 212-9. doi: 10.3945/ajcn.111.022525. PMID: 22170366.

14) Patel MP, Sandige HL, Ndekha MJ, Briend A, Ashorn P, Manary MJ. Supplemental feeding with ready-touse therapeutic food in Malawian children at risk of malnutrition. J Health Popul Nutr. 2005: 351-7. PMID: 16599106.

15) Ackatia-Armah RS, McDonald CM, Doumbia S, Erhardt JG, Hamer DH, Brown KH. Malian children with moderate acute malnutrition who are treated with lipid-based dietary supplements have greater weight gains and recovery rates than those treated with locally produced cereal-legume products: a community-based, cluster-randomized trial. Am J Clin Nutr. 2015; 101(3): 632-45. doi: 10.3945/ajen.113.069807. PMID: 25733649.

16) Zavoshy R, Noroozi M, Jahanihashemi H, Kiamiri D. Nutritional intervention on malnutrition in 3-6 years old rural children in Qazvin Province, Iran. Pak J Biol Sci. 2012; 15(7): 347-52. doi: 10.3923/pjbs.2012.347.352. PMID: 24163961

17) World Health Organization. Vitamin and mineral requirements in human nutrition: report of a joint FAO/WHO expert consultation, Bangkok, Thailand, 21-30 September 1998. World Health Organization; 2004.

18) Fats F.A.O. fatty acids in human nutrition. Report of an expert consultation. FAO Food and nutrition paper. 2010; 91: 1-166.

19) WHO Guidline. potassium intake for adults and children. World Health Organization. 2012: 2.

20) World Health Organization. WHO child growth standards: methods and development: length/height-forage, weight-for-age, weight-for-length, weight-for-height and body mass index-for-age. Geneva: World Health Organization; 2006.

21) World Health Organization. WHO Anthro for personal computers, version 3.2.2, 2011: software for assessing growth and development of the world's children. Geneva: WHO. 2010.

22) Dijkhuizen P. Processed complementary foods in the World Food Programme. Food Nutr Bull. 2000; 21(1): 62-4. doi: 10.1177/156482650002100110.

23) Sotelo A, Arenas M, Hernandez M. Use of chickpea (Cicer arietinum L.) in non-dairy formulas. I. Chemical composition and nutritive quality of chickpeas and a comparison with commercial infant formulas. Arch Latinoam Nutr. 1987; 37(3): 551-9. PMID: 3506409

24) Ulloa J, Valencia M, Garcia Z. Protein concentrate from chickpea: nutritive value of a protein concentrate from chickpea (Cicer arietinum) obtained by ultrafiltration and its potential use in an infant formula. J Food Sci. 1988; 53(5): 1396-8. doi: 10.1111/j.1365-2621.1988.tb09285.x.

25) Milan-Carrillo J, Valdez-Alarcon C, Gutierrez-Dorado R, Cardenas-Valenzuela OG, Mora-Escobedo R, Garzon-Tiznado JA, et al. Nutritional properties of quality protein maize and chickpea extruded based weaning food. Plant Foods Hum Nutr. (Dordrecht, Netherlands). 2007; 62(1): 31-7. doi: 10.1007/s11130006-0039-z. PMID: 17243010.

26) Matilsky DK, Maleta K, Castleman T, Manary MJ. Supplementary feeding with fortified spreads results in higher recovery rates than with a corn/soy blend in moderately wasted children. J Nutr. 2009; 139(4): 773 8. doi: 10.3945/jn.108.104018. PMID: 19225128.

27) Krebs NF, Mazariegos M, Chomba E, Sami N, Pasha O, Tshefu A, et al. Randomized controlled trial of meat compared with multimicronutrient-fortified cereal in infants and toddlers with high stunting rates in diverse settings. Am J Clinl Nutr. 2012; 96(4): 840-7. doi: 10.3945/ajcn.112.041962. PMID: 22952176.

28) Nackers F, Broillet F, Oumarou D, Djibo A, Gaboulaud V, Guerin PJ, et al. Effectiveness of ready-to-use therapeutic food compared to a corn/soy-blend-based pre-mix for the treatment of childhood moderate 
acute malnutrition in Niger. J Trop Pediatr. 2010; 56(6): 407-13. doi: 10.1093/tropej/fmq019. PMID: 20332221.

29) John C, Gopaldas T. Evaluation of the Impact on Growth of a Controlled 6-month Feeding Trial on Children (6-24 Months) Fed a Complementary Feed of a High Energy-Low Bulk Gruel Versus a High Energy-High Bulk Gruel in Addition to Their Habitual Home Diet. J Trop Pediatr. 1993; 39(1): 16-22. PMID: 8383208.

30) Phu PV, Hoan NV, Salvignol B, Treche S, Wieringa FT, Dijkhuizen MA, et al. A six-month intervention with two different types of micronutrient-fortified complementary foods had distinct short-and long-term effects on linear and ponderal growth of Vietnamese infants. J Nutr. 2012; 142(9): 1735-40. doi: 10.3945/jn.111.154211. PMID: 22810985.

31) Dewey KG, Adu - Afarwuah S. Systematic review of the efficacy and effectiveness of complementary feeding interventions in developing countries. Matern Child Nutr. 2008; 4(s1): 24-85. doi: 10.1111/j.17408709.2007.00124.x. PMID: 18289157.

32) Malunga LN, Bar-El SD, Zinal E, Berkovich Z, Abbo S, Reifen R. The potential use of chickpeas in development of infant follow-on formula. Nutr J. 2014; 13(1): 8. doi: 10.1186/1475-2891-13-8. PMID: 24447426.

33) Phuka J, Thakwalakwa C, Maleta K, Cheung YB, Briend A, Manary M, et al. Supplementary feeding with fortified spread among moderately underweight 6 - 18 - month - old rural Malawian children. Matern Child Nutr. 2009; 5(2): 159-70. doi: 10.1111/j.1740-8709.2008.00162.x. PMID: 19292750.

34) Matilsky DK, Maleta K, Castleman T, Manary MJ. Supplementary feeding with fortified spreads results in higher recovery rates than with a corn/soy blend in moderately wasted children. J Nutr. 2009; 139(4): 773 8. doi: 10.3945/jn.108.104018. PMID: 19225128.

35) Locks LM, Manji KP, McDonald CM, Kupka R, Kisenge R, Aboud S, et al. Effect of zinc and multivitamin supplementation on the growth of Tanzanian children aged 6-84 wk: a randomized, placebocontrolled, double-blind trial. Am J Clin Nutr. 2016; 103(3): 910-8. doi: 10.3945/ajcn.115.120055. PMID: 26817503.

36) Hess SY, Abbeddou S, Jimenez EY, Some JW, Vosti SA, Ouedraogo ZP, et al. Small-quantity lipid-based nutrient supplements, regardless of their zinc content, increase growth and reduce the prevalence of stunting and wasting in young burkinabe children: a cluster-randomized trial. PloS one. 2015; 10(3): e0122242. doi: 10.1371/journal.pone.0122242. PMID: 25816354. 